\title{
RISK IDENTIFICATION IN ADOLESCENTS WITH CHRONIC RHEUMATIC DISEASES: THE ROLE OF PEDIATRIC RHEUMATOLOGIST IN TRANSITION CARE
}

Gabriela Coutinho Gondim da Justa (Hospital Geral de Fortaleza, Fortaleza, CE, Brasil), Ana Paula Lopes Pessoa (Universidade de Fortaleza, Fortaleza, CE, Brasil), Miria Paula Vieira Cavalcante (Hospital Geral de Fortaleza, Fortaleza, CE, Brasil), Marco Felipe Castro da Silva (Hospital Geral de Fortaleza, Fortaleza, CE, Brasil), Carlos Nobre Rabelo Júnior (Hospital Geral de Fortaleza, Fortaleza, CE, Brasil), Larissa Elias Pinho (Hospital Geral de Fortaleza, Fortaleza, CE, Brasil)

\section{BACKGROUND}

Transition care is the purposeful, planned movement of adolescents and young adults with chronic physical and medical conditions from childcentred to adult-oriented healthcare systems. Its challenges include gaps in continuity of care, poor adherence, delays in adult services attendance, differences between pediatric and adult centers, difficulties in autonomy over care and unstable medical conditions. In Brazil, few centers focus on transition from pediatric rheumatology. In this study was evaluated the adolescents and their families' perception regarding follow-up and autonomy in health care, as the main risks inherent to this age group.

\section{MATERIALS AND METHODS}

A longitudinal and descriptive study was carried out through interviews, questionnaires and medical records analyzes. Adolescents between 15 and 18 years old regularly followed were included. Patients without definite diagnosis were excluded. Epidemiological and clinical data were collected; selfmanagement and health care utilization skills were evaluated by Transitional Readiness Assessment Questionnaire (TRAQ), a self-administered questionnaire.

\section{RESULTS}

Eighty seven patients were recruited into the transitional service (65 female [74.7\%]). Patients' ages ranged from 15.2 to 18.7 years (median 16.9). Fifty-nine adolescents (73.6\%) considered themselves able to take care of their own follow-up, whereas 39 relatives $(49.3 \%)$ considered the patient capable of doing so. Median disease duration and follow-up were $47(5-180)$ and $33(1-175)$ months, respectively. The mean TRAQ value was 3.30 (1.61 - 4.78). Patients who considered themselves able to take care of their own follow-up had a TRAQ mean higher than those who didn't considered themselves able $(p=0.015)$. The were 270 transitional visits (median 3 visits/patient). Sixty three patients had two or more visits, and an assessment of risks inherent to the age group was made from the second consultation. Fourty-nine (77.8\%) had at least one risk identified. The most prevalent risks were: overweight or obesity $(44.4 \%)$, anxiety (36.5\%), sedentarism (36.5\%), school problems (30.2\%), depression (30.2\%), changes in family structure $(25.4 \%)$, suicidal ideation/self-mutilation $(23.8 \%)$, low selfesteem $(23.8 \%)$. Risks related to psychiatric diseases were identified in 38 patients (60.3\%) and social risks in 37 patientes (58.7\%).

\section{CONCLUSION}

This is one of the first studies on transition care in Brazil focused on risks identification in adolescence. Transition care allows improvement survival and quality of life due to advances in preventive medicine and treatment of chronic rheumatological diseases. The identification of inherent risks, especially psychiatric disorders, plays a fundamental role in the long-term follow-up, making it possible to deliver multidisciplinary and rehabilitation of adolescents. 